\title{
Обеспечение охраны окружающей среды при осуществлении экономической деятельности: международно-правовое регулирование (Часть 2)
}

Пушкарева Э.Ф.*

В статье исследуются три направления в международном праве, дальнейшее развитие которых может привести к повышению эффективности обеспечения охраны окружающей среды при международно-правовом регулировании экономической деятельности. Такими направлениями являются: охрана окружающей среды в рамках ВТО, экологические положения международных инвестиционных соглашений, природоохранная политика международных финансовых институтов.

Ключевые слова: Международное экологическое право; международное экономическое право; экологические положения международных инвестиционных соглашений; природоохранная политика международных финансовых институтов; экологическая политика ВТО.

\section{Природоохранная политика международных финансовых институтов}

Следующей серьезной попыткой обеспечить охрану окружающей среды и рациональной природопользование при решении экономических вопросов стало включение соответствующих положений международными финансовыми институтами в свои политики и процедуры. Кроме того, данные институты часто создают независимый механизм для контроля за выполнением их процедур и политик. Такие механизмы, вслед за Всемирным Банком, были созданы Межамериканским банком развития и Азиатским банком развития. Так как прецедент был создан Всемирным Банком, именно его работа по охране окружающей среды при осуществлении своей деятельности является важной основой для исследования проблем и достижений в данной области.

В попытке выполнить задачи поставленные принципом 21 по экологическому и социальному устойчивому развитию, Всемирный Банк

\footnotetext{
* Пушкарева Эльвира Фаритовна - д.ю.н., ведущий научный сотрудник Центра правовых проблем СОПС при Президиуме РАН.
} 
принял программу действий в четырех частях: обеспечить, чтобы финансируемая Банком деятельность решала экологические проблемы; помогать государствам-членам строить свою жизнь в соответствии с принципами уменьшения бедности, эффективностью экономики и защитой окружающей среды; помогать государствам-членам установить приоритет, создать механизмы и выполнить программы в области охраны окружающей среды; участвовать в решении глобальных экологических задач путем сотрудничества с Глобальным экологическим фондом (ГЭФ).

Сегодня каждый проект, финансируемый Банком, в случае возможного воздействия на окружающую среду, предварительно подлежит всестороннему изучению и оценке на предмет экологического воздействия. Если оценка приводит к выводу о необходимости проведения действий по охране окружающей среды, кредитный договор с Банком будет содержать положения о такой деятельности, а также, обычно, положение о полном или частичном финансировании этой деятельности. Более того, например в 1997 г. Всемирный Банк утвердил 184 проекта, направленных только или в основном на решение экологических проблем.

В дополнение к вышесказанному следует отметить, что Всемирный Банк поддерживает развитие международного права окружающей среды и с использованием других механизмов. С 1984 г. Банк придерживается принципа, что Банк не финансирует проекты, которые противоречат обязательствам кредитуемого государства по международным соглашениям по охране окружающей среды. Данный принцип нашел отражение и в других положениях Банка, таких как Политика в области лесов ${ }^{2}$ и Политика по экологической оценке ${ }^{3}$. Отказываясь финансировать такие проекты, Банк подчеркивает важность данных договоров. Кроме того, Банк содействует вовлечению государств в договоры в области окружающей среды, помогая им выполнить обязательства по договору. Например, Банк способствовал участию в таких договорах Российской Федерации и новых независимых государств ${ }^{4}$.

В целом, можно выделить четыре механизма, посредством которых Всемирный Банк принимает участие в развитии международного права окружающей среды: политики и процедуры Банка в отношении окружающей среды; положения по состоянию окружающей среды в кредитных соглашениях Банка; роль Банка в качестве попечителя и имплементационного органа международных целевых фондов по вопросам 
охраны окружающей среды; и, деятельность Инспекционного Совета Всемирного Банка по охране окружающей среды ${ }^{5}$.

Основы банковской экологической политики заложены в Инструкции по экологической оценке (Operational Policy on Environmental Assessment). Данный документ был принят в 1989 г., еще до признания принципа 17 Декларации Рио. Основной задачей данного документа стало создание такого процесса, в рамках которого проекты финансируемые Банком должны подвергаться специальной оценке. Данная оценка требуется для обеспечения определения экологического эффекта от проектов, финансируемых Банком, с целью принятия мер по минимизации возможных негативных последствий или повышения экологических выгод. В соответствии с данным документом, все проекты классифицируются в зависимости от природы, важности и сложности на три группы. Проекты категории «А» могут повлечь серьезные экологические последствия и поэтому требуют всесторонней полной экологической оценки. Проекты категории «В» могут иметь определенные специфические экологические последствия и потому требуют изучения через менее сложную оценку. Проекты категории «С» не повлекут каких-либо серьезных экологических последствий и, соответственно, не требуют экологической оценки.

Из-за серьезных экологических последствий, которые могут быть вызваны реализацией проекта, проекты находятся под особым контролем в рамках специально разработанных процедур. На самой ранней стадии, во время процесса идентификации проекта и до определения экологической категории проекта, Банк должен обеспечить, чтобы кредитополучатель отобрал независимых, признанных экспертов для определения воздействия реализации проекта на состояние окружающей среды с целью определения категории проекта. Банк должен также обеспечить оценку способности кредитополучателя управлять процессом экологической оценки и установление необходимости создания независимой экологической комиссии, которая обычно формируется при финансировании проектов, реализация которых может привести к серьезным экологическим последствиям.

Инновационным положением процедуры экологической оценки стало требование о том, чтобы органы государств кредитополучателей, которые ответственны за проведение оценки, проводили консультации с «группами, которые окажутся под воздействием проекта и с местными неправительственными организациями по вопросу возможных 
экологических последствий и принимали их мнение во внимание» ${ }^{6}$. (Этот принцип играет большую роль в реализации Принципа 10 Декларации Рио развивающимися государствами и государствами с переходной экономикой). Принцип 10 гласит, что «государства должны поощрять население участвовать в принятии решений делая информацию широко доступной». Политика Банка является еще одной возможностью реализации данного принципа. В соответствии с ней, кредитополучатель обеспечивает своевременный доступ к информации по проекту в той форме и на том языке, который понятен населению. Кредитополучатель также обеспечивает доступ к результатам оценки, а Банк открывает доступ к ним через свой Информационный Центр.

Положения процедурной политики Банка по планам деятельности в области окружающей среды ${ }^{7}$ направлены на подготовку государственного плана действий, направленных на защиту окружающей среды, правительствами государств кредитополучателей. Подготовка таких национальных планов включает глубокий анализ состояния управления природопользованием и охраной окружающей среды с целью определения стратегии решения проблем, которая может быть как кратковременной, так и долговременной. Одним из основных компонентов большинства национальных планов является оценка состояния экологического права государства кредитополучателя. Ключевыми проблемами обычно являются: определение основных проблем негативно влияющих на управление природопользованием и охраной окружающей среды; определение прямых и косвенных причин данных проблем; развитие альтернативных методов управления с целью их устранения; обсуждение источников финансирования, необходимых для осуществления данных задач.

В большинстве случаев полное исследование включает анализ существующих положений действующего законодательства, включая подзаконные правовые акты. Данные положения изучаются с целью определения их соответствия задачам, которые ставит перед собой правительство. После завершения данного анализа, предлагаются рекомендации: разработка и принятие новых законов, уточнение действующего законодательства, кодификация существующих положений в рамках нового закона, совершенствование механизма реализации правовых норм, повышение эффективности институтов. Обычно такие планы ориентируют государства на выполнение международных стандартов в области природопользования и охраны окружающей 
среды. Имплементация данного положения Банка привела к подготовке национальных экологических планов практически всеми государствами кредитополучателями. Национальные планы, в свою очередь, способствуют подготовке планов помощи государствам в области охраны окружающей среды со стороны Всемирного Банка, и других заинтересованных источников финансирования.

Остальные правила Банка ориентированы на поддержку международного права окружающей среды в конкретных областях: сохранение природы, защита лесов, охрана водных ресурсов. Вопросы охраны окружающей среды поднимаются во многих проектах, финансируемых Банком, особенно в области сельского хозяйства, энергетики, транспорта. С целью обеспечения уважения принципов международного права окружающей среды в рамках данных проектов используются различные правовые механизмы. В кредитные соглашения включаются условия, направленные на повышение эффективности выполнения государствами международно-правовых обязательств по защите окружающей среды. Данные условия, на основе соглашения между Банком и государством, могут включаться и развиваться на нескольких стадиях проектного цикла, а их эффективность может быть проверена различными способами.

Во время стадии подготовки проекта и его оценки, особое внимание уделяется мерам по повышению экологических выгод и исключению, или, по крайней мере, уменьшению экологических рисков. Как уже было указано выше, экологическая оценка сегодня является обязательной для любого проекта, финансируемого Банком. Выводы, сформированные на основании оценки, влияют на подготовку проекта, его структуру, а требования по плану экологических действий и мерам, направленным на повышение их эффективности обычно включаются в кредитные соглашения по проектам. План действий или имплементационная программа с подробным описанием действий, которые должен произвести кредитополучатель, обычно оформляются приложением к соглашению о кредите. Как правило, такие программы включают описание основных действий при выполнении проекта, ответственных за выполнение этих действий, а также время или фазы выполнения соответствующей деятельности. Безусловно, эффективность здесь будет зависеть от степени детальности определения временных границ для выполнения каждой задачи, каждого действия. Если на стадии выполнения проекта появятся новые экологические проблемы, 
в имплементационные процедуры могут быть внесены изменения согласно целям проекта. Все это обычно делается без изменения самого соглашения о займе, хотя само соглашение о займе может и включать положение о возможности внесения изменений в процессе выполнения проекта.

Конечно, предусмотренные в договоре положения сами по себе не могут обеспечить выполнение требуемых действий. В условиях договора есть требование к государству кредитополучателю, обеспечить составление отчетов по проекту и регулярно предоставлять их Банку, а персонал Банка регулярно осуществляет контроль за выполнением проекта. Кроме того, по выполнению проекта составляется заключительный отчет с детальным описанием проделанной работы по проекту, их стоимости и результатов. После выполнения проекта, он может быть подвергнут оценке Департаментом по оценке Банка на предмет уровня достижения целей проекта.

При невыполнении обязательств по договору государством кредитополучателем, Банк может применить санкции, как, например, приостановление выплат, прекращение кредитования. Однако наиболее распространенной санкцией, когда проект находится на стадии выполнения, является приостановление выплат. Те же действия могут быть предприняты в случае с грантом Глобального экологического фонда (GEF), как это было в случае с проектом в Конго в 1997 г. ${ }^{8}$ За приостановлением выплат может последовать аннулирование договора, прекращение кредитования, а в особых случаях и повышение суммы выплат по предоставленному кредиту.

Обычно государству сложно справиться со всеми проблемами, возникающими при приостановлении выплат. Кроме того, Банк может даже в этом случае требовать выполнения взятых обязательств. В итоге, если в установленный Банком период времени кредитополучатель все же не выполнил предусмотренные действия, все это может привести к повышению суммы долга, и к требованию Банка немедленно погасить задолженность в полном объеме. Конечно, это достаточно строгая мера со стороны Банка, и, пока, на практике она не применялась. Обычно, невыполнение условий договора ведет к изменению отношений между Банком и государством, и негативно влияет на возможность предоставления Банком последующих кредитов. Здесь важно отметить, что применение санкций будет последним шагом воздействия на государство с целью выполнения им условий проекта. Бесспорно 
также то, что при невыполнении положений проекта Банк скорее будет вести диалог с государством, чем применять санкции. Ведь применение санкций означает прекращение контроля за выполнением проекта, а значит, Банк не сможет влиять на учет заложенных в проекте экологических интересов 9 .

Итак, контроль персонала Банка за выполнением проекта в купе с постоянным диалогом с государством по выполнению эффективности выполнения проекта является гораздо более эффективным средством повышения эффективности выполнения экологических требований при реализации проекта, чем применение санкций. Кроме того, Всемирный Банк не только принял необходимые стандарты по охране окружающей среды, но и создал эффективный механизм для оценки соответствия им своей деятельности. Этот беспрецедентный механизм - Инспекционный Совет Всемирного Банка, сравнить с которым можно разве что механизм рассмотрения индивидуальных жалоб Европейским Судом по правам человека, был создан в 1993 г. Похожие органы позднее были созданы в рамках Банка Межамериканского Развития в 1994 г. и Азиатского Банка Развития в 1995 г., что в очередной раз показывает степень влияния Банка на другие международные финансовые институты.

Инспекционный Совет Всемирного Банка является независимым, постоянным органом в структуре Банка, и состоит из трех членов различных государств-членов Банка, кандидатуры которых выдвигаются Президентом Банка и назначаются Исполнительными директорами Банка сроком на пять лет. Инспекционный Совет был создан для «обеспечения людей, прямо или косвенно пострадавших от проекта, финансируемого Банком специальным механизмом, через который они смогут требовать, чтобы Банк действовал в соответствии со своими политиками и процедурами» ${ }^{10}$. Инспекционному Совету предоставлен мандат исследовать, по разрешению Совета исполнительных директоров Банка, жалобы групп и индивидов (от имени не менее двух лиц), чьи права были нарушены или могут быть нарушены в результате неспособности Банка при осуществлении своей деятельности соответствовать собственным стандартам. Жалобы могут быть также поданы местным представителем пострадавших лиц, Советом исполнительных директоров Банка, и, в некоторых случаях, одним из исполнительных директоров. Чтобы ограничить роль неправительственных организаций, существует положение о том, что неместные представители 
могут представлять пострадавших лишь в исключительных случаях, когда иное подходящее представительство невозможно.

Жалобы должны быть предоставлены в письменной форме и должны содержать информацию о том, как интересы пострадавших были нарушены (или могут быть нарушены) при реализации проекта, финансируемого Банком. Истец должен также доказать, что были исчерпаны все другие средства добиться обоснованного ответа от персонала Банка. После получения жалобы и её изучения, Инспекционный Совет может рекомендовать Совету исполнительных директоров Банка проведение полного расследования. Совет исполнительных директоров Банка обладает полной властью разрешить или отклонить рекомендацию о полном расследовании. До 1999 г. Исполнительные директора часто отклоняли рекомендации Инспекционного Совета о проведении расследования. Вместо этого принималось решение о необходимости составления Администрацией Банка «планов действий», что означало, что жалобы уже не будут подвергнуты полной оценке, а имплементация плана действий не будет находиться под серьезным наблюдением. Более того, истцы при таких решениях не получали реальной возможности доказать свою правоту. После внесения изменений 1999 г., Совет исполнительных директоров Банка поддержал все рекомендации о расследовании.

После получения разрешения на полное расследование, Инспекционный Совет ведет свою работу, используя также свое право на доступ ко всем материалам Банка. После расследования Инспекционный Совет предоставляет доклад с оценкой выполнения Банком своих внутренних правил. В течение 6 недель Администрация Банка должна предоставить Совету исполнительных директоров Банка доклад и рекомендации в соответствии с выводами Инспекционного Совета. Доклад Инспекционного Совета, рекомендации Администрации Банка и решение Совета исполнительных директоров Банка публикуются через две недели после решения Совета исполнительных директоров Банка.

Согласно выводам Инспекционного Совета Всемирный Банк не всегда следует своим правилам и процедурам. Для примера можно посмотреть отчёты Инспекционного Совета по управлению лесами (Камбоджи, 2006) ${ }^{11}$, по созданию транспортной инфраструктуры в Мумбаи (Индия, 2005) ${ }^{12}$, по проекту газовых трубопроводов (Нигерия, 2008) ${ }^{13}$. Большинство жалоб касаются защиты окружающей среды 
и прав человека. В качестве иллюстрации, можно привести пример из деятельности Инспекционного Совета ${ }^{14}$.

В мае 1996 года Международная Ассоциация Развития (IDA) выдала кредит на 63 миллиона долларов на проект по улучшению состояния окружающей среды и социального уровня в секторе угольной промышленности в Индии. Первоначально планировалось усовершенствовать 25 шахт, а затем 495. Вопрос о соблюдении процедур встал по поводу только одной шахты - в районе Парей Ист - где две деревни пострадали от действий по развитию шахты. В 2001 г. Бина Станис, представитель местной неправительственной организации, представляя интересы Парей Ист, подала требование о проведении инспекции. Истцы жаловались, что не получили честной и адекватной компенсации за изъятые земли и деревни. Поэтому бывшие землевладельцы теперь вынуждены жить в колониях, без права собственности на землю, и не могут заниматься привычным делом. Все эти нарушения были подтверждены Инспекционным Советом. В частности, Инспекционный Совет отметил, что в рамках существующих правил Банка, предпочтение отдается подходу «земля за землю», то есть при выполнении проекта населению должна оказываться помощь в поиске другого участка земли, а не просто денежная компенсация. В то время как компания Coal India Ltd. пошла путем выплаты компенсации, да и то, не всегда адекватной. ${ }^{15}$

В рамках данного дела, по вопросам окружающей среды было поднято несколько важных проблем. Прежде всего, вопрос о защите лесов. В иске говорилось о том, что местные жители в качестве неформального дохода всегда использовали природные ресурсы, в частности ресурсы леса. При развитии шахт было уничтожено много участков леса, а работы по его восстановлению не были проведены. Следующий важный вопрос касался охраны верхнего почвенного слоя и ресторации почвы для сельскохозяйственных целей. Инспекционный Совет не получил каких-либо доказательств того, что работы по реабилитации земли вообще планировалась.

Несколько жалоб от населения поступило и по поводу ухудшения качества воды. Администрация Банка, прежде всего, указала на факт того, что ежемесячно Институтом планирования шахт составляется доклад о качестве воздуха, воды и уровне шума. Инспекционный Совет был ознакомлен с системами очистки использованной воды, и качество воды соответствовало стандартам. Важное замечание Инспекционного Совета касалось складирования отходов на территории шахт - данное 
место было недостаточно надежно отгорожено от сельскохозяйственной земли. Поэтому Инспекционный Совет рекомендовал уделить большее внимание мониторингу за обращением с отходами. Еще одним вопросом была проблема доступа к воде, так как в Пинде, куда было переселено 20 семей, доступ к воде обеспечен не был, а колодцы были установлены только через 6 недель после переселения, а положения о доступе к воде вообще не было в планах подготовки к переселению, что, несомненно, является нарушением правил Банка.

В соответствии с ответом Администрации Банка от 2002 г., наблюдательные миссии посещали Парей Ист с 1996 г. по 2001 г. 18 раз; с 1997 года свою работу по независимой оценке деятельности компании Coal India Ltd. проводит Экологический и социальный комитет, в который входят и международные эксперты; а компания (CCL) дала согласие оказать помощь всем тем, кто пострадал в районе Парей Ист. Инспекционный Совет положительно отметил в своём докладе намерение Администрации Банка продолжать контроль за выполнением проекта и после выдачи кредита.

В июле 2003 г. Совет директоров обсудил представленный Инспекционным Советом доклад по проведенной инспекции, ответ и рекомендации Администрации Банка. Совет директоров согласился с выводами Инспекционного Совета, отметив вместе с тем тот факт, что в целом данный проект оказал позитивное экологическое и социальное воздействие на политику индийской угольной компании и почти 90 \% тех, кто понес ущерб в Парей Ист, получили компенсацию до завершения проекта. Совет директоров утвердил План действий Администрации Банка, в соответствии с которым контроль и мониторинг данного проекта будет продолжаться, и Совету директоров будут представляться регулярные доклады. Кроме вопроса компенсации тем, кому был нанесен ущерб при выполнении проекта, Совет директоров также выделил важность выполнения положений по охране окружающей среды. Прежде всего, это качество воды в новых местах жительства переселенного населения, и возвращение земель сельскохозяйственного назначения. В 2004 г. Компания CCL проинформировала о том, что было посажено 17000 деревьев, проведена другая работа по улучшению качества окружающей среды. Наблюдение за качеством воды со стороны Банка будет продолжаться дальше.

С целью повышения эффективности деятельности Инспекционного Совета, в литературе предлагаются следующие рекомендации: 
Всемирный Банк должен более чётко определить правила, касательно защиты окружающей среды; неправительственные организации должны получить право подавать иски в Инспекционный Совет в защиту публичных интересов; мандат Инспекционного Совета должен быть расширен, и включать осуществление контроля за выполнением рекомендаций, предложенных Инспекционным Советом после проведённого расследования, а также превентивную функцию ${ }^{16}$. Тем не менее, важно понимать, что сам факт проводимого Инспекционным Советом расследования, уже благотворно влияет на эффективность выполнение правил Всемирного Банка.

\section{Основные выводы}

Всемирный Банк не только принял необходимые стандарты в области охраны окружающей среды, но и создал эффективный контрольный механизм для оценки соответствия своей деятельности принятым им самим высоким стандартам ${ }^{17}$. Однако, несмотря на существование Инспекционного Совета, Всемирный Банк не всегда следует своим внутренним правилам. Соответственно, своевременным представляется провести некоторые изменения. Например, Банк должен провести деятельность по уточнению своих процедур и политик, особенно это касается вопросов охраны окружающей среды, так как в данной области политики Банк должны быть точными и четкими, ясными для понимания и применения. В тех же случаях, когда Инспекционный Совет получил от Банка недостоверную информацию, важно выяснять причины таких ошибок со стороны персонала Банка. Важной проблемой является и кратковременность улучшений после проведения расследований Инспекционным Советом. Представляется, что для долговременного устойчивого улучшения ситуации мандат Инспекционного Совета должен включать превентивные меры, мониторинг после проведенного расследования и право Инспекционного Совета давать рекомендации после проведенного расследования.

\section{Заключение}

Международно-правовое регулирование экологически обоснованной экономической деятельности, несмотря на тот факт, что сегодня государства ещё не в полной мере готовы к дальнейшему продвижению этой идеи, будет только совершенствоваться. Представляется, что невысокая эффективность для защиты окружающей среды от закрепления 
экологических положений в международных инвестиционных и торговых соглашениях объясняется, прежде всего, именно этой неготовностью. Когда рассматривается спор, экономические интересы всегда превалируют над экологическими. Редкие исключения имеют место, когда дело касается защиты человеческой жизни и его здоровья (Asbestos case; Brazilian tyres case; Methanex v. US case), и только одно - направлено исключительно на защиту окружающей среды (US - Shrimp case 2). Представляется, что на сегодняшний день наиболее эффективным механизмом учёта экологических интересов при международно-правовом регулировании экономической деятельности являются международные финансовые институты, ведь при осуществлении соответствующей деятельности они не мотивированы получением прибыли - экологические меры являются обязательным условием получения кредита, а не дополнительной нагрузкой инвестора или торговой кампании.

Экологически обоснованная экономическая деятельность должна стать важной частью международно-правового регулирования, так как это соответствует идеям прогрессивного развития международного права. Как определил Международный суд ООН в деле Gabcikovo/ Nagymaros: «Необходимость соотносить экономическое развитие с защитой окружающей среды частично выражена в концепции устойчивого развития» ${ }^{18}$.

${ }^{1}$ OP 4.36 - Forests. URL:

http://web.worldbank.org/WBSITE/EXTERNAL/PROJECTS/EXTPOLICIES/EXTOPMA NUAL/0,,contentMDK:20064668 menuPK:64701637 pagePK:64709096 piPK:6470910 8 theSitePK:502184 isCURL:Y,00.html (дата обращения: 05.11. 2012)

${ }^{2}$ OP 4.01 - Environmental Assessment. URL:

http://web.worldbank.org/WBSITE/EXTERNAL/PROJECTS/EXTPOLICIES/EXTOPMA NUAL/0,,contentMDK:20064724 menuPK:64701637 pagePK:64709096 piPK:6470910 8 theSitePK:502184,00.html (дата обращения: 07.11. 2012).

${ }^{3}$ Participation of the Russian Federation and Newly Independent States of the former Soviet Union in the International Environmental Agreements / World Bank, Environmental Department. March 1996.

${ }^{4}$ I.F.I.Shihata. The World Bank's Contribution to the Development of International Environmental Law / Liber Amicorum / Ed. G.Hafner and others. The Hague/London/ Boston, 1998. P. 634.

${ }^{5}$ OP 4.01. URL: 
http://web.worldbank.org/WBSITE/EXTERNAL/PROJECTS/EXTPOLICIES/EXTOPMA NUAL/0,,contentMDK:20064724 menuPK:64701637 pagePK:64709096 piPK:6470910 8 theSitePK:502184,00.html (дата обращения: 10.11.2012).

${ }^{6}$ OP 4.02 - Environmental Action Plans. URL:

http://web.worldbank.org/WBSITE/EXTERNAL/PROJECTS/EXTPOLICIES/EXTOPMAN UAL/0, contentMDK:20064606 pagePK:64141683 piPK:64141620 theSitePK:502184,00. html (дата обращения: 10.11.2012).

${ }^{7}$ Shihata I. The World Bank Inspection Panel: In Practice. Oxford, 2001.

${ }^{8}$ Более подробно с данным положением можно ознакомиться I.Shihata. Implementation, Enforcement and Compliance with International Environmental Agreements-Practical Suggestions in Light of the World Bank's Experience // Georgetown International Environmental Law Review. 1996. V. 9. P. 47-51; P. Sand. International Economic Instruments for Sustainable Development : Sticks, Carrots and Games // Indian Journal of International Law. 1996. V. 36(2). P. 1-16.

${ }^{9}$ The International Bank for Reconstruction and Development (IBRD) (Resolution No. 93-10) and the International Development Association (IDA) (Resolution No. 93-6) / The Inspection Panel for the International Bank for Reconstruction and Development and International Development Association, Operating Procedures // ILM. 1995. V. 34.

${ }^{10}$ Inspection Panel Investigation Report regarding Cambodia: Forest Concession Management and Control Pilot Project (2006). URL: http://web.worldbank.org/WBSITE/EXTERNAL/ EXTINSPECTIONPANEL/0,,menuPK:64132057 pagePK:64130364 piPK:64132056 th eSitePK:380794,00.html (дата обращения: 15. 11.2012).

${ }^{11}$ Inspection Panel Investigation Report regarding India: Mumbai Urban Transport Project (2005). URL: http://web.worldbank.org/WBSITE/EXTERNAL/EXTINSPECTIONPANE L/0,,menuPK:64132057 pagePK:64130364 piPK:64132056 theSitePK:380794,00.html (дата обращения: 15. 11.2012).

${ }^{12}$ Inspection Panel Investigation Report regarding Ghana/Nigeria: West African Gas Pipeline Project (2008). URL: http://web.worldbank.org/WBSITE/EXTERNAL/EXTINSPECTION PANEL/0,,menuPK:64132057 pagePK:64130364 piPK:64132056 theSitePK:380794,00. $\mathrm{html}$ (дата обращения: 15. 11.2012).

${ }^{13}$ О других делах из практики Инспекционного Совета: Нурмухаметова Э.Ф. Инспекционная Комиссия Всемирного Банка: вклад в устойчивое развитие // Московский журнал международного права. 2006. № 4. С. 129-145.

${ }^{14}$ Было отмечено нарушение следующих процедур: Involuntary Resettlement (OD 4.30), Indigenous Peoples (OD 4.20), Environmental Assessment (OD 4.01), Project Supervision (OD 13.05), Disclosure of Information (BP 17.50), and Management of Cultural Property (OPN 11.03).

${ }^{15}$ I.Shihata. The World Bank Inspection Panel - Its Historical, Legal and Operational Aspects / The Inspection Panel of the World Bank: a Different Complaints Procedure / Ed. by G.Alfredsson and R.Ring. 2001; A.G.Gualtieri. The Environmental Accountability of the World Bank to Non-State Actors: Insights from the Inspection Panel // The British Year Book of International Law. 2001; I. Shihata. The World Bank Inspection Panel: In Practice. Oxford, 2001; D. Hunter. Using the World Bank Inspection Panel to Defend the Interests of Project-Affected People // Chi. J. Int'l L. 2003. V. 4. P. 210; A. Umana. Some Lessons from the Inspection Panel's Experience / The Inspection Panel of the World Bank: a Different Complaints Procedure / Ed. G. Alfredson and R. Ring. 2001. P. 138; E. Nurmukhametova. 
Several Problems Concerning the Efficiency of the World Bank Inspection Panel activity. P. 422.

${ }^{16}$ См. об Инспекционном Совете Всемирного Банка: www.inspectionpanel.org.

${ }^{17}$ Gabčíkovo-Nagymaros Project (Hungary/Slovakia) (Order) [1997] ICJ Rep 3. 


\section{Enforcement of the Environmental Protection by the means of Economic Activity Regulations: International Law Perspective}

\section{(Part 2)}

(Summary)

Elvira F. Pushkareva*

The articles addresses three directions in the International law, those developments may lead to the efficiency increase of in enforcement of the environmental protection by the means of Economic Activity Regulations. Those directions include the Environmental Protection in the WTO, Environmental Provisions of International Investment Agreements and Environmental Policy of the International Financial Institutions.

Keywords: International Environmental Law; International Economic Law; Environmental Provisions of International Investment Agreements; Environmental Policy of the International Financial Institutions; Environmental Protection in the WTO.

*Elvira F. Pushkareva-Doctor of Laws, Senior Researcher, Center for Reproductive Forces, Russian Academy of Sciences. 